OKU Journal of Natural and Applied Sciences
Volume 4, Issue 2, 124-133, 2021

\title{
Deprem Etkisinde Çok Katlı Betonarme Bir Binanın TDY-2007 ve TBDY-2018 Deprem Yönetmeliklerine Göre Eşdeğer Deprem Yüklerinin Karşıllaştırılması
}

\author{
Alper ÖZMEN ${ }^{1 *}$, Erkut SAYIN ${ }^{2}$ \\ ${ }^{1}$ İnönü Üniversitesi, Mühendislik Fakültesi, İnşaat Mühendisliği Bölümü, 44000, Malatya \\ ${ }^{2}$ Fırat Üniversitesi, Mühendislik Fakültesi, İnşaat Mühendisliği Bölümü, 23000, Elâzı ̆̆ \\ ${ }^{1}$ https://orcid.org/ 0000-0003-1335-3780 \\ ${ }^{2}$ https://orcid.org/ 0000-0003-0266-759X \\ *Sorumlu yazar: alper.ozmen@inonu.edu.tr
}

\begin{tabular}{|c|c|}
\hline Araştırma Makalesi & ÖZET \\
\hline $\begin{array}{l}\text { Makale Tarihçesi: } \\
\text { Geliş tarihi: } 21 \text { Eylül } 2020 \\
\text { Kabul tarihi:3 Şubat } 2021 \\
\text { Online Yayınlanma: } 1 \text { Haziran } 2021\end{array}$ & $\begin{array}{l}\text { Deprem yapılar üzerinde yıkıma sebep olan en önemli etkenlerden biridir. Aktif } \\
\text { olan bir deprem sistemi üzerinde yer alan ülkemizde meydana gelen depremler } \\
\text { önemli can ve mal kayıplarına yol açmaktadır. Bu sebeple depremin yapıların } \\
\text { tasarımı esnasında en gerçekçi şekliyle hesap edilmesi ve tasarımların bu esasa } \\
\text { göre yapılması büyük önem taşımaktadır. Deprem etkisinin yapılara uygulanması } \\
\text { için çeşitli hesap yöntemleri kullanılmaktadır. Bu yöntemlerden uygulaması en } \\
\text { basit ve anlaşılır olanı Eşdeğer Deprem Yükü Yöntemidir. Deprem etkileri bu } \\
\text { yöntemde belirli koşulların sağlanması durumunda Eşdeğer Deprem Yükleri } \\
\text { olarak adlandırılan yatay yüklerle temsil edilirler. Bu çalışmada, beş katlı düzenli } \\
\text { betonarme bir yapı tasarlanarak Eşdeğer Deprem Yükü Metodu kullanılarak TDY- } \\
2007 \text { ve TBDY-2018'e göre yappya ait periyot, mod şekilleri, taban kesme kuvveti } \\
\text { ve kat yer değiştirmeleri elde edilmiştir. Yapılan çözümlerde farklı yerel zemin } \\
\text { sınıfları dikkate alınmıştır. Çözümlerde SAP2000 yapısal analiz programı } \\
\text { kullanılmıştır. Çalışma sonucunda } 2018 \text { deprem yönetmeliğinin daha gerçekçi ve } \\
\text { güvenilir sonuçlar ortaya koyduğu görülmüştür. }\end{array}$ \\
\hline
\end{tabular}

Comparison of Equivalent Earthquake Loads According to TEC-2007 and TBEC-2018 Earthquake Regulations of a Multi-Storey Reinforced Concrete Building Under Earthquake Effect

\section{Research Article}

\section{Article History:}

Received: 21 September 2020

Accepted: 3 February 2021

Published online: 1 June 2021

\section{Keywords:}

Earthquake codes

Base shear force

TBEC-2018

TEC-2007 \begin{abstract}
The earthquake is the one of most important effect which causing destruction on structures. Turkey is located on the active earthquake zone. The earthquake in this zone cause significant loss of life and property. Therefore, earthquake effect needs to be calculated in the most realistic form. There are different calculation methods for applying the earthquake effect to structures. The simplest and most understandable of these methods is the Equivalent Seismic Load Method. In this method Earthquake effects are represented by horizontal loads called Equivalent Seismic Loads. In this study, a five-storey regular reinforced concrete structure was designed. Period, mode shapes, base shear force and floor displacement are obtained according to TEC-2007 and TBEC-2018 regulations with Equivalent Seismic Load Method. Different local soil classes were taken into consideration in the solutions. For the solutions, SAP2000 structural analyses software was used. As a result of this research, it was observed that the TBEC-2018 presented more realistic and reliable results.
\end{abstract}

To Cite: Özmen A., Sayın E. Deprem Etkisinde Çok Katlı Betonarme Bir Binanın TDY-2007 ve TBDY-2018 Deprem Yönetmeliklerine Göre Eşdeğer Deprem Yüklerinin Karşılaştırılması. Osmaniye Korkut Ata Üniversitesi Fen Bilimleri Enstitüsü Dergisi 2021; 4(2): 124-133. 


\section{Giriş}

Türkiye, dünyada meydana gelen depremlerin \%17'sinin oluştuğu Alp-Himalaya deprem kuşağında bulunmaktadır. $\mathrm{Bu}$ sebeple Türkiye depremselliği yüksek olan ülkelerden biridir [1]. ABD'de yaşanan büyük depremler sonucu, yaklaşı 20 y1l önce ortaya performansa göre tasarım ve değerlendirme kavramı çıkmış ve bugün çağdaş ülkelerin deprem yönetmeliklerinde kendine yer bulmaya başlamıştır [2-4]. Dünyadaki bu geliş̧melere paralel olarak Türkiye'de 2007 yılında çıan deprem yönetmeliğinde betonarme binaların deprem performanslarının belirlenmesi ve değerlendirilmesi amaciyla doğrusal elastik ve doğrusal elastik olmayan, statik ve dinamik tabanlı hesap yöntemleri belirtilmiştir [5]. 2018 y1lında yayınlanan Türkiye Bina Deprem Yönetmeliğinde (TBDY 2018) binaların deprem performanslarının belirlenmesi amacıyla doğrusal ve doğrusal olmayan hesap yöntemleri ortaya konmuştur. Doğrusal hesap yöntemleri Eşdeğer Deprem Yükü Yöntemi ve Modal hesap yöntemleridir. Doğrusal olmayan hesap yöntemleri ise İtme Yöntemleri ve Zaman Tanım Alanında hesap yöntemleridir.

Yönetmelikte yer alan bu hesap yöntemleri içerisinde en kolay uygulanabilir ve anlaşılır olanı Eşdeğer Deprem Yükü Metodudur. Bu metotta yatay deprem kuvvetleri bazı katsayılar kullanılarak elde edilmektedir. Bu çalışmada TDY 2007 ve TBDY 2018 yönetmeliklerinde alınan katsayılar ve bu katsayılar sonucu elde edilen deprem kuvvetleri ve bu kuvvetlerin düzenli 5 katlı bir betonarme yap1 üzerindeki etkileri karşılaştırılmıştır $[6,7]$. Bu konuda son yıllarda yapılan benzer çalışmalar aşağıda sunulmuştur.

Koçer ve ark. [8], TDY 2007 ve TBDY 2018 de tanımlanan spektral ivme değerleri ile zemin hâkim periyotlarını, risk durumuna göre dört farklı il ve farklı yerel zemin sınıfları için elde etmişlerdir. Bu çalışma kapsamında dört farklı il ve farklı zemin sınıfları için TDY 2007 ve TBDY 2018'de yer alan tasarım spektrumlarından, spektral ivme değerleri elde edilmiş ve bu değerler arasında karşılaştırma yapılmıştır. Çalışma sonucunda zayıf zemin grupları için TBDY 2018'in TDY 2007'ye göre daha gerçekçi ve güvenilir sonuçlar verdiği görülmüştür. Taşkın [9] yaptığ1 çalışmada Eurocode 8 (EC 8), American Society of Civil Engineers 7 (ASCE 7) ve Türkiye Deprem Yönetmeliği 2007 (TDY 2007)'ye göre 12 kattan oluşan betonarme bir yapıyı hem Eşdeğer Deprem Yükü Metodu ile hem de Mod Birleştirme Metodu ile çözmüştür.
Yapılan çözümde SAP2000 V15 programı kullanılmıştır. Yapıların bulundukları ülkelerde depremin en yıkıcı etkiyi oluşturduğu bölgede oldukları kabul edilmiştir. Yapılan çalışma sonucunda ise en elverişsiz durumların Eurocode 8 (EC)'e göre elde edildiği en düşük kesit tesirlerinin ise Türkiye Deprem Yönetmeliği 2007'ye göre elde edildiği ortaya konulmuştur. Ayrica Eurocode 8 (EC 8), American Society of Civil Engineers 7 (ASCE 7) yönetmeliklerinde yük kombinasyonları birbirine yakın katsayılar içerdiği için kesit tesirleri de oldukça birbirine yakın çıkmıştır.

Özer ve Yüksel [10] yaptıkları çalışmada deprem etkilerinin betonarme çerçeveler ve perdelerle birlikte karşılandığ etkilerini Türkiye Deprem Yönetmeliği 2007 (TDY 2007) ve Türkiye Bina Deprem Yönetmeliğine (TBDY 2018) göre karşılaştırmışlardır. Bu çalışma kapsamında örnek yap1 olarak rijit bodrum +13 katlı bir yapıyı ele almışlardır. Dalyan ve Şahin [11] yaptıkları araștırmada mevcut 5 katlı betonarme bir konutun TDY 2007 ve TBDY 2018'e göre Doğrusal Olmayan Artımsal İtme Analizi yöntemiyle deprem etkisi altında taşıyıcı sistem performansını analiz etmiştir ve elde edilen sonuçları karşılaştırmışlardır.

$\mathrm{Bu}$ çalışmada, beş katlı düzenli betonarme bir yapı tasarlanarak Eşdeğer Deprem Yükü Yöntemi (EDYY) ile TDY-2007 ve TBDY-2018 deprem yönetmelikleri esas alınarak yapıya ait periyotlar, mod şekilleri, taban kesme kuvvetleri ve kat deplasmanları farklı yerel zemin sınıfları için elde edilmiştir. Elde edilen sonuçlara göre 2007 ve 2018 deprem yönetmelikleri karşılaştırılmıştır. Çözümlerde SAP2000 yapısal analiz programı kullanılmıştır [12].

\section{Materyal ve Metot}

Bu çalışmada, beş katlı düzenli betonarme bir yapı tasarlanarak Eşdeğer Deprem Yükü Yöntemi ile TDY-2007 ve TBDY-2018 yönetmeliklerine göre deprem analizleri yapılmıştır. $\mathrm{Bu}$ çalışma kapsaminda TDY-2007 ve TBDY-2018 yönetmeliklerinde yer alan deprem hesap yöntemlerinden Eşdeğer Deprem Yükü Metoduna ait kısımlar incelenmiştir. Her iki yönetmelik genel olarak incelendiğinde iki yönetmelik arasındaki en büyük farkların etkin kesit rijitliği ve hasar sınırı tarifleri üzerinde olduğu görülüyor. Ayrıca Eşdeğer deprem yükü yöntemi özelinde bakıldığında hesap metodunda önemli bir değişiklik olduğu görülmektedir. Ayrıca TDY 2007'de yerel zemin grupları ve yerel zemin 
sınıflandırılması ayrı yapılmışken TBDY 2018 de yerel zemin grupları kaldırılıp yerel zemin sınıfları daha geniş bir çerçevede ele alınmıştır. Ayrıca altı farklı gruba ayrılan yerel zemin sinıfi içinde kötü zeminleri temsil eden ZF adlı zemin için ekstra şartlar getirilmiştir. TBDY 2018 yönetmeliğinde iyi yerel zemin sınıfları için dikkate alınan kısa periyot tasarım spektral ivme katsayısı ve 1 saniyelik periyot için tasarım spektral ivme katsayısı değerleri kötü yerel zemin sınıfları için dikkate alınan değerler ile karş1laştırıldığında daha küçüktür bu nedenle iyi zeminlerde eşdeğer deprem yükü metodunda daha küçük deprem kuvvetleri yapıya etki ettirilmektedir.

\subsection{Deprem Bölgelerinde Yapılacak Binalar Hakkında Yönetmelik (TDY 2007)}

TDY-2007'de yer alan Eşdeğer Deprem Yükü Metoduna göre taban kesme kuvveti (Vt) aşağıda yer alan Denklem (1) ile hesaplanmaktadır.

$$
V t=\frac{W \cdot A(T 1)}{R a(T 1)} \geq 0,10 A_{0} I W
$$

Yukarıda verilen denklemde W; yapının türüne bağlı olarak seçilen hareketli yük katılım katsayısı katılarak hesaplanan ağırlığını, $\mathrm{T}_{1}$; yapıya ait birinci doğal titreşim periyodunu, $\mathrm{A}(\mathrm{T} 1)$; Yapının 1. periyoduna karşılık spektral ivme katsayısını, $\mathrm{R}_{\mathrm{a}}(\mathrm{T} 1)$; yapının 1. doğal titreşim periyoduna karşılık gelen deprem yükü azaltma katsayısını, $\mathrm{A}_{0}$; deprem bölgesine bağlı olarak elde edilen etkin yer ivmesi katsayısını, I; ele alınan yapının kullanım amacına bağlı olarak elde edilen bina önem katsayısını, Vt; toplam eşdeğer deprem yükünü göstermektedir.

Ele alınan yapının birinci doğal titreşim periyodu Denklem (2) ile elde edilir.

$$
T_{1}=2 \pi\left(\frac{\sum_{\mathrm{i}=1}^{N} m_{i} d_{f i}^{2}}{\sum_{i=1}^{N} F_{f i} d_{f i}}\right)^{1 / 2}
$$

Denklem (2.2)'de yer alan $\mathrm{m}_{\mathrm{i}}$; binanın dikkate alınan katının kütlesini, $\mathrm{F}_{\mathrm{fi}}$; dikkate alınan kata etkiyen fiktif yükü, $\mathrm{d}_{\mathrm{fi}}$; dikkate alınan kattaki fiktif yer değiştirmeyi göstermektedir. Denklem (2) kullanılarak elde edilen değer dikkate alınmaksızın, bodrum katları dikkate alınmayan durumda kat sayısı $\mathrm{N}>13$ olan binalar için doğal titreşim periyodu $0,1^{*} \mathrm{~N}^{\prime}$ den fazla olamaz.
Denklem (1)'de bulunan diğer bir ifade Spektral ivme katsayısı olan A(T), Denklem (3) ile hesaplanır.

$$
\mathrm{A}(\mathrm{T})=\mathrm{A}_{0} \mathrm{IS}(\mathrm{T})
$$

Denklem (3)'te $\mathrm{S}(\mathrm{T})$; spektrum katsayısını göstermektedir. Denklem (3)'te yer alan $\mathrm{A}_{0}$ ve I değerleri sirasılyla Deprem Bölgelerinde Yapılacak Binalar Hakkında Yönetmelik 2007 (TDY 2007) Tablo 2.2. ve Tablo 2.3'e göre elde edilir.

Spektrum katsayısı olan S(T), Şekil 1'de verilen TDY-2007 tasarım spektrumuna göre belirlenir.

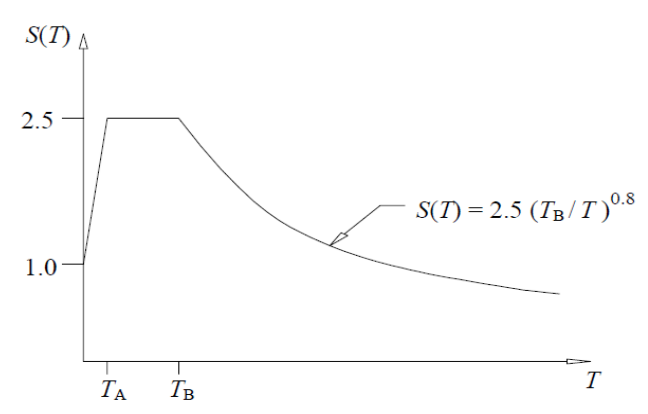

Şekil 1. TDY 2007'ye göre elastik tasarım ivme spektrumu

Spektrum katsayısı S(T)'nin hesabı Denklem (4)' te verilmiştir. TDY-2007 tasarım spektrumu $\% 5$ sönüm oranına göre tanımlanmıştır ve tasarım depreminin, bina önem katsayısı (I), 1,0 olan binalarda Elli yıllık bir süreçte aşılma olasıllı̆ $\% 10$ 'dur.

$$
\begin{aligned}
& S(T)=1+1,5 T \frac{T}{T_{A}} \quad 0 \leq T \leq T_{A} \\
& S(T)=2,5 \quad T_{A} \leq T \leq T_{B} \\
& S(T)=2,5\left(\frac{T_{B}}{T}\right)^{0,8} \quad T_{B} \leq T
\end{aligned}
$$

Denklem (4)'te $\mathrm{T}$; binaya ait doğal titreşim periyodunu, $\mathrm{T}_{\mathrm{A}}, \mathrm{T}_{\mathrm{B}} ;$ spektrum karakteristik periyotların1 belirtmektedir. Spektrum karakteristik periyotları olan $T_{A}$ ve $T_{B}$ değerleri TDY 2007 Tablo 2.4'ten yerel zemin sinıfına göre elde edilmektedir.

Deprem yükü azaltma katsayısı, $\mathrm{R}_{\mathrm{a}}(\mathrm{T})$ ile gösterilir ve yapının doğrusal elastik olmayan davranışını hesaba katmak amacıyla kullanılır. Denklem (5)'e göre hesaplanır. Denklemde verilen R; taşıyıcı sistem davranış katsayısını göstermektedir. Yapının taşıyıcı sistem tipine bağlı olan taşıyıcı sistem davranış katsayısı TDY2007 Tablo 2.5'ten elde edilmektedir. 


$$
\begin{array}{ll}
R_{a}(T)=1,5+(R-1,5) \frac{T}{T_{A}} & 0 \leq T \leq T_{A} \\
R_{a}(T)=1,5+(R-1,5) \frac{T}{T_{A}} & 0 \leq T \leq T_{A}
\end{array}
$$

Binanın kullanma amacına bağlı olarak belirlenen hareketli yük katılım katsayısı TDY-2007 Tablo 2.7'den elde edilir. Bina katlarına dağıttılacak olan toplam deprem yükü Denklem (6)'da verilmiştir.

$$
V_{t}=\Delta F_{N}+\sum_{i=1}^{N} F_{i}
$$

Denklem (8)'de $\Delta \mathrm{F}_{\mathrm{N}}$; binanın çatı katına etkimekte olan ek eşdeğer deprem yükünü, $F_{i}$; binanın dikkate alınan katına etkiyen eşdeğer deprem yükünü ifade etmektedir. Denklem (7)'de yer alan N; binanın temel üstü seviyesinden veya rijit bodrum katı varsa zemin kat döşemesinin üzerinden itibaren toplam kat sayısını ifade etmektedir.

$$
\Delta \mathrm{F}=0,0075 \mathrm{NVt}
$$

Denklem (1) ile hesaplanan toplam deprem yükü binanın kat seviyelerine dağıtımı Denklem (8)'e göre yapılır.

$$
F_{i}=\left(V_{t}-\Delta F_{N}\right) \frac{w_{i} H_{i}}{\sum_{j=1}^{N} w_{j} H_{j}}
$$

Denklem (8)'de $\mathrm{H}_{\mathrm{i}}$; binanın i'inci katının temelden itibaren yüksekliğini ifade etmektedir. Yapıda rijit davranan bodrum varsa yükseklik zemin kat döşemesinden başlayarak yükseklik dikkate alınmaktadır.

TDY-2007'ye göre EDYY'nin kullanımı belli şartlarla kısıtlanmıştır. Bu kısıtlamada yapıda bulunan deprem düzensizlikleri ve toplam bina yüksekliği önemlidir. Eşdeğer Deprem Yükü

\begin{tabular}{|c|c|c|}
\hline $\begin{array}{l}\text { Deprem } \\
\text { Bölgesi }\end{array}$ & Bina Türü & $\begin{array}{l}\text { Toplam } \\
\text { Yükseklik } \\
\text { Sinırı } \\
\left(\mathrm{H}_{\mathrm{N}}\right)\end{array}$ \\
\hline 1,2 & $\begin{array}{l}\text { Burulma düzensizliği katsayısı } \\
\text { olan gösterilen } \eta_{b i} \text { nin her bir } \\
\text { katta } 2,0 \text { 'den küçük olduğu } \\
\text { binalar. }\end{array}$ & $\leq 25 \mathrm{~m}$ \\
\hline 1,2 & $\begin{array}{l}\text { Burulma düzensizliği katsayıs } \\
\text { olan gösterilen } \eta_{\text {bi' nin her bir }} \\
\text { katta } 2,0 \text { 'den küçük olduğu ve }\end{array}$ & $\leq 40 \mathrm{~m}$ \\
\hline
\end{tabular}
Yönteminin uygulanabileceği binalarla ilgili kısıtlamalar, Tablo 1'de gösterilmiştir.

Tablo 1. Eşdeğer Deprem Yükü Metodunun uygulanabileceği binalarla ilgili kısıtlamalar [6]. ayrıca B2 türünde düzensizliğin

olmadı ̆̆ binalar

3, 4 Diğer tüm binalar

$\leq 40 \mathrm{~m}$

\subsection{Türkiye Bina Deprem Yönetmeliği-2018} (TBDY 2018)

TBDY-2018'de yer alan Eşdeğer Deprem Yükü Metoduna göre, $\mathrm{x}$ yönünde yapıya tesir eden toplam eşdeğer deprem yükü Denklem 9 ile hesaplanmaktadır.

$$
\mathrm{Vt}_{E}(x)=m_{t} S_{a R}\left(T_{p}(x)\right) \geq 0,04 m_{t} I S_{D S} g
$$

$\mathrm{Bu}$ denklemde $\mathrm{S}_{\mathrm{aR}}\left(\mathrm{T}_{\mathrm{p}}(\mathrm{X})\right)$; azaltılmış tasarım spektral ivmesini ifade etmektedir ve hesaplanmasında $\mathrm{X}$ doğrultusunda binanın doğal titreșim periyodu $T_{p}(X)$; göz önüne alınmaktadır. $\mathrm{S}_{\mathrm{DS}}$ ise kısa periyot için tanımlanan tasarım spektral ivme katsayısı olarak ifade edilmektedir. I; bina önem katsayısını ve g, yerçekimi ivmesini ifade etmektedir. $\mathrm{m}_{\mathrm{t}}$, binanın toplam kütlesine karşl1ık gelmektedir.

Azaltılmış tasarım spektral ivme $\mathrm{S}_{\mathrm{aR}}(\mathrm{T})$ hesabı Denklem 10' da verilmiștir.

$$
S_{a R}(T)=\frac{S_{a e}(T)}{R_{a}(T)}
$$

Burada $R_{a}(T)$ ve $S_{a e}(T)$ sırasıyla, deprem yükü azaltma katsayısını ve DD-2 güçlü yer hareketi için yatay elastik tasarım spektral ivmeyi ifade etmektedir. Bu ifadeler, aşağıda yer alan Denklem (11) ve (12) yardımıyla hesaplanmaktadır.

$$
\begin{aligned}
& R_{a}(T)=\frac{R}{I} \quad \mathrm{~T}>\mathrm{T}_{\mathrm{B}} \\
& R_{a}(T)=D+\left(\frac{R}{I}-D\right) \frac{T}{T_{B}} \quad \mathrm{~T} \leq \mathrm{T}_{B}
\end{aligned}
$$

Yukarıdaki denklemde $\mathrm{R}$, taşıyıcı sistem türüne bağl1, taşıyıcı sistemin davranış katsayısı, D ise dayanım fazlalığ 1 katsayısı olarak ifade edilmektedir.

$$
\begin{array}{lrl}
S_{a e}(T)=\left(0,4+0,6 \frac{T}{T_{A}}\right) S_{D S} & 0 \leq T \leq T_{A} \\
S_{a e}(T)=S_{D S} & T_{A} \leq T \leq T_{B} \\
S_{a e}(T)=\frac{S_{D l}}{T} & T_{B} \leq T \leq T_{L} \\
S_{a e}(T)=\frac{S_{D l} T_{L}}{T^{2}} & T_{L} \leq T
\end{array}
$$


Burada, $S_{D S}$ ve $S_{D 1}$ sirasiyla k1sa periyot ve 1,0 saniye periyot tasarım spektral ivme katsayılarını, $T$ ise yapının doğal titreşim periyodunu, $T_{A}$ ve $T_{B}$ yatay tasarım spektrum köşe periyotlarını ve $T_{L}$ sabit yer değiştirme bölgesine geçiş periyodunu (6s) göstermektedir. $S_{D S}$ ve $S_{D 1}$ ifadeleri Denklem 13'e göre belirlenir. $T_{A}$ ve $T_{B}$ ifadeleri ise Denklem 14'e göre elde edilir.

$S_{D S}=S_{S} F_{S}$

$S_{D 1}=S_{1} F_{1}$

$T_{A}=0,2 \frac{S_{D l}}{S_{D S}}$

$T_{B}=\frac{S_{D l}}{S_{D S}}$

Kisa periyoda esas tasarım spektral ivme katsayısına bağlı elde edilen ve yapıların deprem hesabında tasarımında kullanılacak olan Deprem tasarım sinıfları (DTS) ise TBDY-2018 Tablo 3.2'den elde edilmektedir. Denklem 13 ve 14 'te, yer alan $S_{S}, S_{1}, F_{S}$ ve $F_{1}$ ifadeleri sirasiyla, kisa periyot için harita spektral ivme katsayısını, 1,0 saniyelik periyot için harita spektral ivme katsayısını, kısa periyot bölgesi için yerel zemin etki katsayısını ve 1,0 saniyelik periyot için yerel zemin etki katsayısını belirtmektedir. $\mathrm{Bu}$ katsayılar yerel zemin sinifi ve harita spektral ivme katsayılarına göre TBDY-2018 Tablo 2.1 ve Tablo 2.2'den elde edilir. Harita spektral ivme katsayıları, belirlenen bir deprem için referans zemin koşullarında ve $\% 5$ sönüm oranında AFAD Deprem Tehlike Haritasında verilen harita spektral ivmelerinin yerçekimi ivmesine (g) bölünmesi sonucunda hesaplanmaktadır.

$\mathrm{Bu}$ denklemde yer alan $\mathrm{T}_{\mathrm{p}}(\mathrm{x})$ binanın hâkim doğal titreşim periyodunu, $m_{i}$ herhangi bir i. katın toplam kütlesi, $d_{\text {fi }}(x)$ herhangi bir i. katın üzerine etkiyen deprem kuvveti (fiktif yük) etkisinde yaptığ 1 yer değiştirmeyi, $\mathrm{F}_{\mathrm{fi}}$ herhangi bir i. kata uygulanan fiktif yükü, $\mathrm{N}$ ele alınan binanın toplam kat sayısını ifade etmektedir. TBDY-2018'e göre tanımlanmış olan spektrum eğrisi Şekil 2'de görülmektedir.

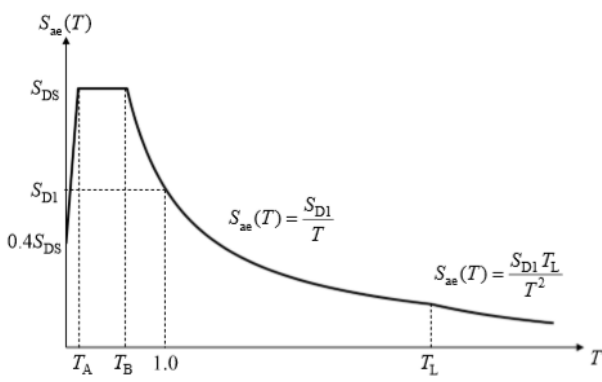

Şekil 2. Yatay elastik tasarım ivme spektrumu [7]

\section{Sayısal Çalışma}

Çalışma kapsamında 5 katlı, $\mathrm{x}$ ve y yönlerinde iki açıklığa sahip açıklıkları $5 \mathrm{~m}$, kat yüksekliği $3 \mathrm{~m}$ olan betonarme bir bina SAP2000 yapisal analiz programında modellenmiştir. Yapıya ait geometrik özellikler Şekil 3'te görülmektedir.

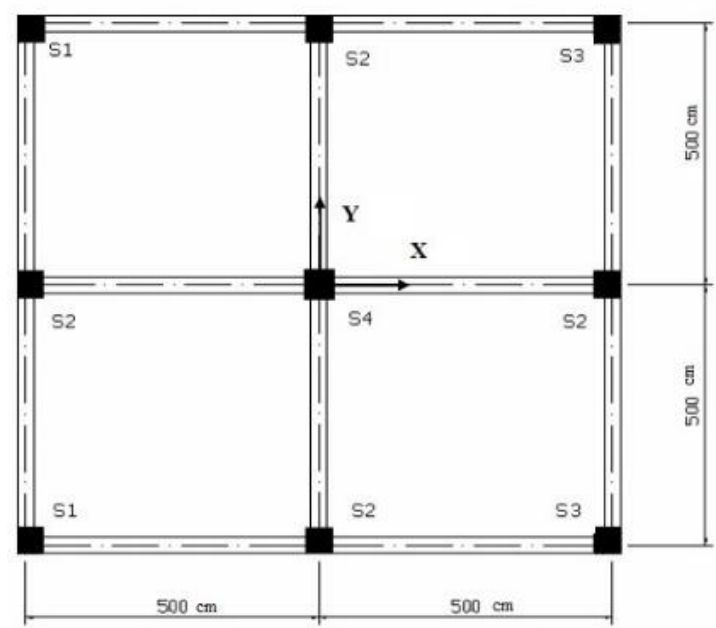

Şekil 3. Örnek yapıya ait kat planı

Döşemelerin rijit diyafram olarak çalıştığı kabul edilerek, kat seviyelerindeki dügüm noktalarına rijit diyaframlar atanmıştır. Örnek yapıya ait bilgiler Tablo 3'te sunulmuştur. Yap1 kolon ve kirişlerden oluşan çerçeve bir sistem olarak modellenmiştir. Döşemeler shell (kabuk) eleman olarak tanımlanmıştır. Yapının radye temel üzerine oturduğu kabul edilerek kolonlar tabana ankastre olarak mesnetlenmiştir. Kullanım amacı olarak konut kabul edilmiştir. Yapının taşıyıcı sistem türü çerçeve, süneklik düzeyi ise yüksek olarak dikkate alınmıştır. Yapı yerinde dökme betonarme bir yapidir.

Tablo 3. Örnek yapıya ait bilgiler

\begin{tabular}{ll|ll}
\hline Bilgiler & $\begin{array}{l}\text { TDY } \\
2007 ’ e \\
\text { göre }\end{array}$ & Bilgiler & $\begin{array}{l}\text { TBDY } \\
2018 ' e \\
\text { göre }\end{array}$ \\
\hline $\begin{array}{l}\text { Beton-Çelik } \\
\text { Sinıf }\end{array}$ & C25/30 & Beton-Çelik Sınıf & C25/30 \\
\hline $\begin{array}{l}\text { Kiriş Ölçüleri } \\
(\mathrm{cm})\end{array}$ & $25 \times 50$ & Kiriş Ölçüleri $(\mathrm{cm})$ & $25 \times 50$ \\
\hline
\end{tabular}




\begin{tabular}{|c|c|c|c|}
\hline $\begin{array}{l}\text { Kolon Ebatları } \\
(\mathrm{cm})\end{array}$ & $50 \times 50$ & $\begin{array}{l}\text { Kolon Ebatları } \\
(\mathrm{cm})\end{array}$ & $50 \times 50$ \\
\hline $\begin{array}{l}\text { Döşeme kalınlığ } 1 \\
(\mathrm{~cm})\end{array}$ & 12 & $\begin{array}{l}\text { Döşeme kalınlığ } 1 \\
(\mathrm{~cm})\end{array}$ & 12 \\
\hline $\begin{array}{l}\text { Bina önem } \\
\text { katsayısı (I) }\end{array}$ & 1.0 & $\begin{array}{l}\text { Bina kullanım } \\
\text { sinıfı (BKS) }\end{array}$ & 3 \\
\hline $\begin{array}{l}\text { Etkin Yer İvme } \\
\text { Katsayısı }\left(\mathrm{A}_{\mathrm{O}}\right)\end{array}$ & 0,30 & $\begin{array}{l}\text { Bina yükseklik } \\
\text { sinıf (BYS) }\end{array}$ & 6 \\
\hline \multirow[t]{4}{*}{$\begin{array}{l}\text { Hareketli yük } \\
\text { katılım kats. }\end{array}$} & 0,3 & $\begin{array}{l}\text { Bina Önem } \\
\text { Katsayısı (I) }\end{array}$ & 1,0 \\
\hline & & $\begin{array}{l}\text { Deprem Tasarım } \\
\text { Sınıfı (DTS) }\end{array}$ & 2 \\
\hline & & $\begin{array}{l}\text { Dayanım fazlalı̆̆ } 1 \\
\text { kats. }\end{array}$ & 3 \\
\hline & & $\begin{array}{l}\text { Hareketli yük } \\
\text { katılım kats. }\end{array}$ & 0,3 \\
\hline
\end{tabular}

Oluşturulan sayısal modellerde kullanılan ölü(sabit) ve hareketli yüklerin belirlenmesinde TS-498'den yararlanılmıştır.

Yapının modellenmesinde, beton birim hacim

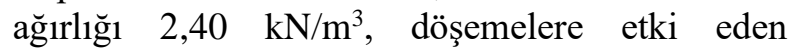
hareketli yük normal katlarda $2 \mathrm{kN} / \mathrm{m}^{2}$, en üst katta $1,5 \mathrm{kN} / \mathrm{m}^{2}$, döşemelere etki eden ilave ölü yük $1,50 \mathrm{kN} / \mathrm{m}^{2}$ ve kiriş üzerine ise duvar yükü $6,25 \mathrm{kN} / \mathrm{m}^{2}$ olarak tanımlanmıștır. SAP2000 programinda yapilan analiz sonucunda TDY2007'e göre elde edilen yapıya ait hâkim periyot değerleri $\mathrm{x}$ ve y yönünde $0,78735 \mathrm{~s}$ olarak elde edilirken, TBDY-2018'e göre etkin kesit rijitlikleri dikkate alınarak yapılan deprem analizi sonucunda ise yapının $\mathrm{x}$ ve y yönündeki periyodu 1,0982 s bulunmuştur. Yapının deprem hesabına esas olan ağırlığ $6191,25 \mathrm{kN}$ olarak elde edilmiştir. Yapının SAP2000'de modellenmiş üç boyutlu durumu Şekil 4'te gösterilmiştir. TBDY2018'e göre Eşdeğer deprem yükü hesabında göz önüne alınacak olan yapının etkili doğal titreşim periyodunun elde edilişi Denklem 15 kullanılarak aşağıdaki hesaplarda gösterilmiştir.

$$
T_{p A}=c_{T} H_{N}^{3 / 4}
$$

$\mathrm{C}_{\mathrm{t}}=0,1$ (sadece çerçeve tipi taşıyıcıdan oluşan binalarda) olarak dikkate alınmıştır. $\mathrm{H}_{\mathrm{N}}=15,00 \mathrm{~m}$ SAP2000 analizlerinden elde edilen periyotlar:

$\mathrm{T}_{\mathrm{p}}{ }^{(\mathrm{x})}=1,0982 \mathrm{~s}, \mathrm{~T}_{\mathrm{p}}{ }^{(\mathrm{y})}=1,0982 \mathrm{~s}$

$\mathrm{X}$ doğrultusu için;

$\mathrm{T}_{\mathrm{pA}}=0,1 \times(15) 3 / 4=0,76 \mathrm{sn}$

$1,4 \times T_{p A} \geq T_{p}(X)$ olmalıdı;

$1,4 x T_{p A}=1,064 \mathrm{~s} \leq T_{p}{ }^{(X)}=1,0982 \mathrm{~s} \rightarrow T_{p}{ }^{(X)}=1,064$

$\mathrm{s}$ değeri hesaplarda dikkate alınır.

$\mathrm{Y}$ doğrultusu için;

$\mathrm{T}_{\mathrm{pA}}=0,1 \times(15) 3 / 4=0,76 \mathrm{sn}$

$1,4 \times T_{p A} \geq T_{p}^{(\mathrm{y})}$ olması gerektiği için;
$1,4 \times T_{p A}=1,064 \mathrm{~s} \leq T_{p}^{(\mathrm{y})}=1,0982 \mathrm{~s} \rightarrow T_{p}^{(\mathrm{y})}=1,064$ $\mathrm{s}$ değeri hesaplarda dikkate alınır.

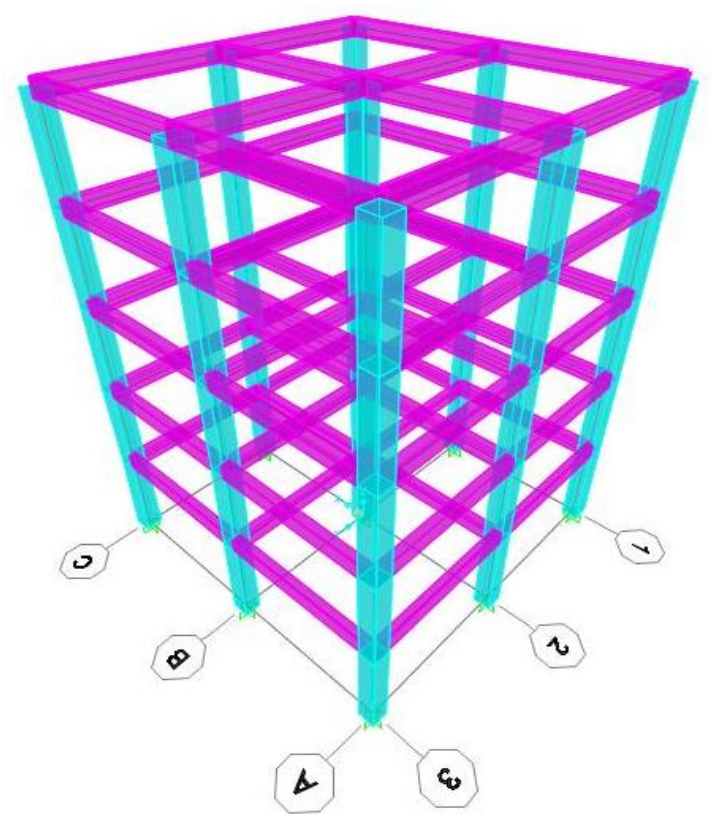

Şekil 4. Yapının üç boyutlu modeli

Analizler sonucunda TDY-2007 ve TBDY-2018 yönetmeliklerine göre yapıya ait periyot değerleri Tablo 4'te görülmektedir. Tablo 4'e bakıldığında her iki yönetmeliğe göre elde dilen periyotlar arasında farklılık olduğu görülmektedir. Periyot değerlerinin farklı çıkmasının temel nedeni 2018 yönetmeliğinde kesit atalet momentlerinin etkin kesit rijitlikleriyle çarpılarak dikkate alınmasındandır. Çalışmada sunulan örnek yapıda kolonlar 0,70, kirişler 0,35 değerleriyle çarpılarak analizler yapılmıştır [13]. TDY 2007 ve TBDY 2018'e göre oluşturulan modellere ait ilk üç mod şekli Şekil 5 'te sunulmuştur.

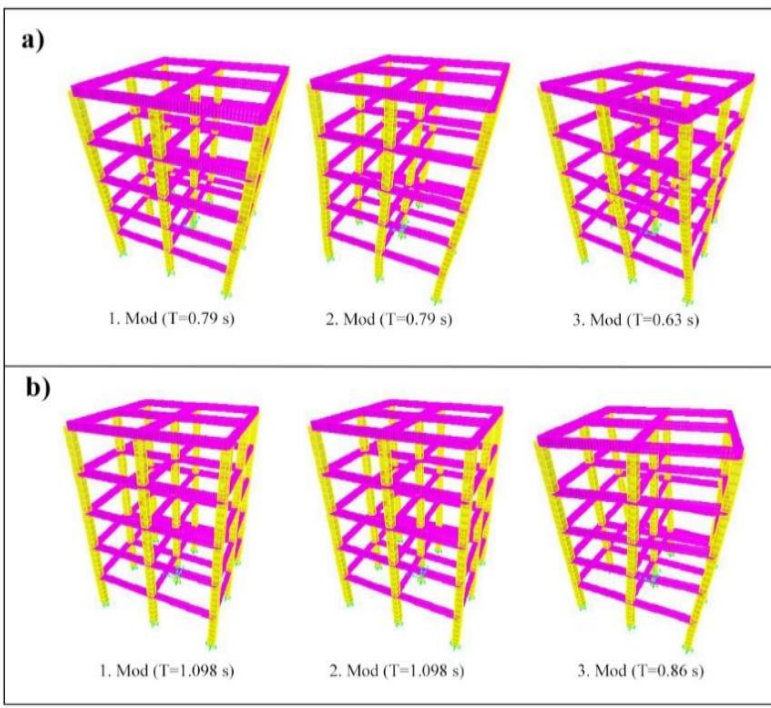

Şekil 5. Yapının ilk 3 mod şekli ve periyotları (a) TDY- 2007 (b) TBDY-2018 modeli 
Tablo 4. Modellere ait periyot değerleri

\begin{tabular}{lll}
\hline Mod & $\begin{array}{l}\text { TDY-2007'ye göre T } \\
\text { (sn) }\end{array}$ & $\begin{array}{l}\text { TBDY-2018'e göre } \\
\text { (sn) }\end{array}$ \\
\hline $\mathbf{1}$ & 0,7873 (x doğrultusu) & 1,0982 (x doğrultusu) \\
\hline $\mathbf{2}$ & 0,7873 (y doğrultusu) & 1,0982 (y doğrultusu) \\
\hline $\mathbf{3}$ & 0,6268 (Burulma) & 0,8555 (Burulma) \\
\hline $\mathbf{4}$ & 0,2412 (x doğrultusu) & 0,3257 (x doğrultusu) \\
\hline $\mathbf{5}$ & 0,2412 (y doğrultusu) & 0,3257 (y doğrultusu) \\
\hline $\mathbf{6}$ & 0,1940 (Burulma) & 0,2583 (Burulma) \\
\hline
\end{tabular}

TDY 2007'ye göre çalışma kapsamında dikkate alınan yapının bulunduğu Malatya ili $2^{0}$ deprem bölgesinde yer aldı ̆̆ 1 için 2007 deprem yönetmeliğine göre yapılan hesaplarda $2^{0}$ deprem bölgesine ait değerler dikkate alınmıştır. TBDY2018'e göre Malatya Yeşilyurt Enlem 38,285064, Boylam 38,328289 koordinatlarında, DD-2 deprem yer hareketi düzeyi dikkate alınarak, TBDY-2018'de yer alan tüm yerel zemin sinıfları (ZA-ZE)için ayrı ayrı taban kesme kuvvetleri elde edilmiştir. TDY-2007'e göre tanımlanmış olan yerel zemin sınıflarının (Z1-Z4) her biri için taban kesme kuvvetleri bulunmuştur. Daha önce yapılmış benzer çalışmalarda TBDY-2018'deki $\mathrm{ZA}, \mathrm{ZB}, \mathrm{ZC}$, ZD ve ZE yerel zemin siniflarının TDY-2007'deki karşılıkları sırasıyla Z1, Z2, Z3 ve Z4 olarak gösterilmiştir [11,14]. Analizlerden her iki yönetmeliğe göre elde edilen $\mathrm{x}$ ve $\mathrm{y}$ doğrultusundaki taban kesme kuvvetleri Tablo 5 'te görülmektedir. Her iki yönetmeliğe göre yapılan analizler sonucu ortaya çıkan taban kesme kuvvetlerinin grafik halinde karşılaştırılması ise Şekil 6'da verilmiştir. Taban kesme kuvvetlerinin $\mathrm{X}$ ve $\mathrm{Y}$ doğrultusunda farklı çıkmasının temel nedeni farklı yük kombinasyonları uygulanmış olması ve bunlardan en gayri müsait durumda elde edilen zarf yük kombinasyonu sonucunda elde edilen değerlerin dikkate alınmasıdır.

Tablo 5. Taban kesme kuvvetleri

\begin{tabular}{|c|c|c|c|c|}
\hline \multirow[b]{3}{*}{ Yerel Zemin Sinıfi } & \multicolumn{4}{|c|}{ Taban Kesme Kuvveti (kN) } \\
\hline & \multicolumn{2}{|c|}{ TBDY 2018} & \multicolumn{2}{|c|}{ TDY 2007} \\
\hline & $\mathbf{X}$ & $\mathbf{Y}$ & $\mathbf{X}$ & $\mathbf{Y}$ \\
\hline ZA-Z1 & 139,4 & 181,22 & 245,6 & 368,94 \\
\hline ZB-Z1 & 139,4 & 181,22 & 245,6 & 368,94 \\
\hline ZC-Z2 & 261,1 & 339,43 & 309,2 & 422,63 \\
\hline ZD-Z3 & 366,1 & 475,93 & 427,7 & 584,48 \\
\hline ZE-Z4 & 532,8 & 692,64 & 558,7 & 726,31 \\
\hline
\end{tabular}

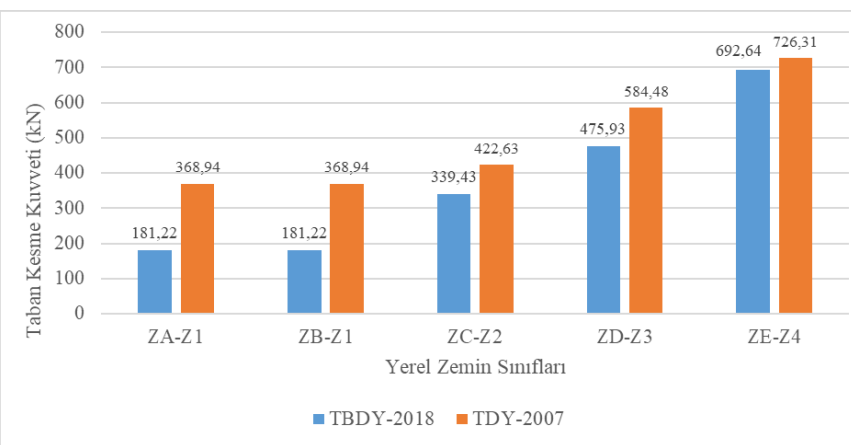

Şekil 6. Yerel zemin sınıflarına göre taban kesme kuvvetleri

Yapıda her iki yönetmeliğe göre en büyük taban kesme kuvvetleri y doğrultusunda elde edilmiştir. Şekil 6 incelendiğinde TBDY-2018'e göre yapılan analizlerden elde edilen taban kesme kuvvetlerinde TDY-2007'e göre ZA, ZB, ZC, ZD ve $Z E$ yerel zemin sınıfları için sırayla, $\% 50,9$, $\% 50,9, \% 19,7, \% 18,6$ ve $\% 4,6$ azalma olduğu görülmüştür. ZE yerel zemin sinifinda ise değişimin çok az olduğu görülmektedir.

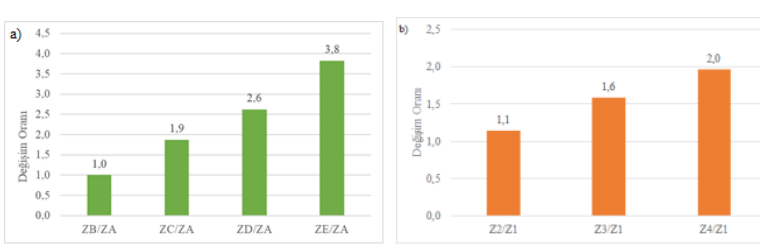

Şekil 7. ZA ve Z1 yerel zemin sınıflarına göre taban kesme kuvvetinin değişimi (a) TBDY-2018 (b) TDY2007

TBDY-2018 hesaplarından elde edilen taban kesme kuvvetlerinin ZA yerel zemin sinifi referans alınarak diğer zemin sınıflarına göre değişim oranları Şekil 7a'da verilmiştir. TDY2007 için ise taban kesme kuvvetlerinin Z1 yerel zemin sınıfını referans alınarak diğer zemin sinıfları için değișim oranları ise Șekil $7 b$ 'de gösterilmektedir. Şekil 7a incelendiğinde ZA yerel zemin sinıfı referans alınarak $Z B, Z C, Z D$ ve $Z E$ yerel zemin sınıfları için taban kesme kuvvetinde sirasiyla $1,0,1,9,2,6$ ve 3,8 kat artış olduğu görülmüştür. Şekil $7 \mathrm{~b}$ incelendiğinde ise $Z 1$ yerel zemin sınıfına göre Z2, Z3 ve Z4 yerel zemin sinıfları için taban kesme kuvvetinde sırasıyla 1,1, 1,6 ve 2,0 kat artış olduğu belirlenmiştir.

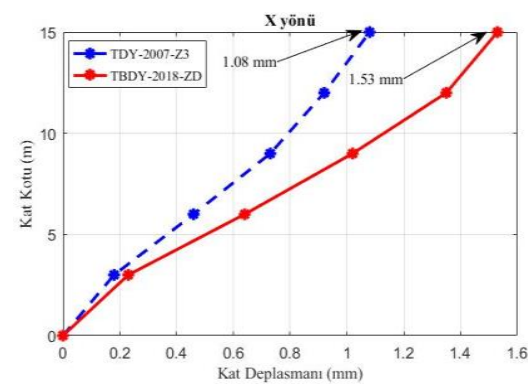



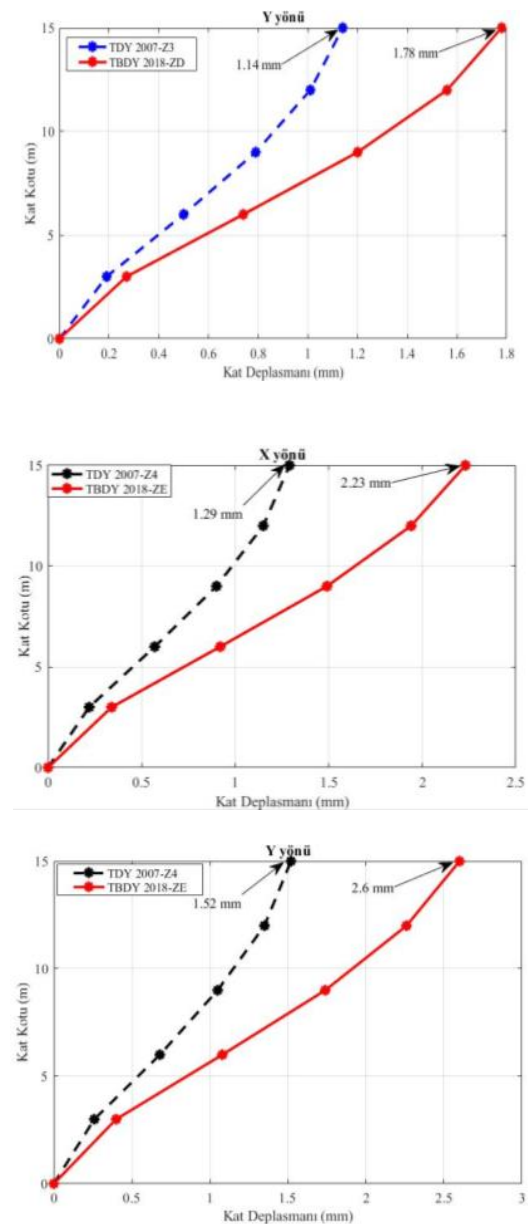

Şekil 8. TDY 2007 ve TBDY 2018' e göre elde edilen kat deplasmanları

2007 ve 2018 deprem yönetmeliklerine göre Z3ZD ve Z4-ZE yerel zemin sınıfları için katların yaptığ1 deplasmanlar Şekil 8'de görülmektedir. Z3 yerel zemin sınıfı için maksimum deplasman y yönünde $1,14 \mathrm{~mm}, \mathrm{ZD}$ yerel zemin sınıfı için y yönünde $1,78 \mathrm{~mm}, \mathrm{Z} 4$ yerel zemin sınıfı için $\mathrm{y}$ yönünde $1,52 \mathrm{~mm}$ ve $Z E$ yerel zemin sınıf için $y$ yönünde $2,6 \mathrm{~mm}$ olarak elde edilmiştir. TBDY 2018'e göre maksimum deplasman ZD yerel zemin sınıfı için Z3 yerel zemin sınıfına göre $\% 56$ artış gösterirken 2018 deprem yönetmeliğine göre ZE yerel zemin sınıfı için Z4 yerel zemin sınıfina göre $\% 71$ artış gösterdiği görülmüştür. Daha önce yapılmış olan benzer çalışmalarda, deplasmanlarda meydana gelen artış, TBDY 2018 de yer alan deplasman spektrumundaki artışla açıklanmıştır [14]. Buna ek olarak 2018 deprem yönetmeliğinde iyi zeminler için taban kesme kuvvetleri 2007 deprem yönetmeliğine göre daha düşük olmasına rağmen kat deplasmanlarının büyük olmasının bir diğer nedeni de etkin kesit rijitlikleri nedeniyle yap1 periyodunun 2018 deprem yönetmeliğinde daha büyük olmasıdır. Ayrica yerel zemin sinıfi Z3'ten Z4 ve ZD'den ZE'ye değiştiğinde maksimum kat deplasmanlarında sırasıyla $\% 33$ ve $\% 46$ artış olduğu görülmüştür. Bu değişimde 2018 deprem yönetmeliğinde yer alan etkin kesit rijitliklerinin kullanılmasının etkili olduğu düşünülmektedir [15].

\section{Sonuçlar}

TBDY 2018 ve TDY 2007'de yer alan EDYY ait esaslar dikkate alınarak seçilen düzenli çok katlı betonarme yap1 modeli üzerinde yapılan hesaplar neticesinde elde edilen sonuçlar aşağıda sıralanmıştır.

1. Yapının 2007 ve 2018 deprem yönetmeliklerine göre elde edilen periyotları farklı değerler almıştır. TBDY 2018'e göre elde edilen periyotlar daha büyük çıkmıştır. $\mathrm{Bu}$ farkın ortaya çıkmasında 2018 deprem yönetmeliğine göre etkin kesit rijitliklerinin dikkate alınıyor olması ve hesaplarda kullanılacak periyot hesabında yapının etkili doğal titreşim periyodunun hesaplanması olarak gösterilebilir.

2.TBDY-2018 referans alınarak yapılan analizlerden elde edilen taban kesme kuvvetlerinde TDY-2007 referans alınarak elde edilen taban kesme kuvvetlerine göre tüm yerel zemin sınıflarında azalma olduğu görülmüştür. TBDY-2018'e göre yapılan analizlerden elde edilen deprem yüklerinin tüm yerel zemin sinıfları için TDY-2007'ye göre elde edilen deprem yüklerinden daha düşük olduğu görülmüştür. TBYD-2018'e göre elde edilen sonuçlara göre yapı periyodunda artış meydana gelmiştir ve yapının doğal periyotlarında meydana gelen artış sonucu TBDY 2018'e göre yapılan analizlerden elde edilen taban kesme kuvvetlerinde azalma meydana gelmiştir.

3. TBDY-2018'e göre yapılan hesaplar sonucunda elde edilen taban kesme kuvvetlerinde 2018 deprem yönetmeliği esas alınarak elde edilen yerel zemin sinıfları arasinda taban kesme kuvvetinin değişimi TDY-2007'ye göre belirgin bir artış göstermiştir.

4. TBDY 2018 referans alınarak hesaplanan kat deplasmanlarının ZD yerel zemin sınıfı için Z3 yerel zemin sinıfina göre ve ZE yerel zemin sinıfi için Z4 yerel zemin sınıfina göre artış gösterdiği görülmüştür.

İyi yerel zemin sinıfından kötü yerel zemin sınıfina doğru elde edilen kat deplasmanlarının her iki yönetmelik için de arttığ görülmüştür. Ancak 2018 deprem yönetmeliğine göre elde edilen deplasmanlar 2007 deprem 
yönetmediğinden elde edilenlere göre daha fazla artış göstermiştir.

5. TBDY 2018 dikkate alınarak yapılan analizler zemin etkisinin hesaplarda daha gerçekçi olarak etki ettiğini göstermektedir.

Yerel zemin sınıfının sağlam zeminden daha kötü bir zemine doğru değişmesiyle taban kesme kuvvetlerinde görülen artış miktarının TDY 2007'ye kıyasla TBDY 2018'de daha fazla olduğu görülmüsşür.

Farklı yükseklikte veya deprem düzensizlikleri bulunan bina modelleri kullanılarak yapılacak olan benzer nitelikteki çalışmaların, bu çalışma sonucunda elde edilen verilerin değerlendirilmesi ve geliştirilmesi açısından yararlı olacağ 1 düşünülmektedir.

\section{Çıkar Çatışması Beyanı}

Makale yazarları aralarında herhangi bir çıkar çatışması olmadığını beyan ederler.

\section{Araştırmacıların Katkı Oranı Beyan Özeti}

Yazarlar makaleye eşit oranda katkı sağlamış olduklarını beyan ederler.

\section{Kaynakça}

[1] Ünal A. TDY 2007'ye göre tasarlanmamış betonarme çerçevelerin düzlem dişi perde duvarla güçlendirilmesi, Yüksek Lisans Tezi, Selçuk Üniversitesi Fen Bilimleri Enstitüsü, sayfa no: 354, Konya, Türkiye, 2012.

[2] Türker K., Yavaş A. Türkiye deprem yönetmeliğindeki performans değerlendirme yöntemlerinin karşılaştırılması, Balıkesir Üniversitesi Fen Bilimleri Enstitüsü Dergisi 2016; 13(2): 85-96.

[3] Mwafy A., Elnashai AS. Static pushover versus dynamic collapse analysis of rc buildings, Engineering Structures 2001; 23(5): 407-424.

[4] Krawinkler H., Seneviratna G. Pros and cons of a pushover analysis of seismic performance evaluation, Engineering Structures 1998; 20(4-6): 452-464.

[5] Agency FEM. Prestandard and commentary for the seismic rehabilitation of buildings.
American Society of Civil Engineers (ASCE) 2000.

[6] TC Bayındırlık ve İskân Bakanlığı, Deprem bölgelerinde yapılacak binalar hakkında yönetmelik, Ankara, Türkiye, 2007.

[7] Türkiye Bina Deprem Yönetmeliği, Afet ve Acil Durum Yönetimi Başkanlığı, Resmî Gazete, Say1: 30364 (Mükerrer), 2018.

[8] Koçer M., Nakipoğlu A., Öztürk B., Alhagri MG., Arslan MH. Deprem kuvvetine esas spektral ivme değerlerinin TBDY 2018 ve TDY 2007'ye göre karşılaştırılması, Selçuk-Teknik Dergisi 2018; 17(2): 43-58.

[9] Taşkın T. Çok katlı bir betonarme yapının farklı ülke yönetmeliklerine göre tasarımı, Yüksek Lisans Tezi, İstanbul Teknik Üniversitesi Fen Bilimleri Enstitüsü, İstanbul, Türkiye, 2012.

[10] Özer Ö., Yüksel B. Deprem etkilerinin betonarme çerçeveler ile boşluklu betonarme perdeler tarafından birlikte karşılandığ 1 yüksek binaların analiz sonuçlarının TBDY, (2018) ve DBYBHY,(2007)'ye göre karşılaştırılması, Niğde Ömer Halisdemir Üniversitesi Mühendislik Bilimleri Dergisi 2020; 9(2): 931-945.

[11] Dalyan İ., Şahin B. Mevcut betonarme bir binanın 2007 ve 2018 deprem yönetmeliklerine göre deprem yükleri altındaki taşıyıcı sistem performansının değerlendirilmesi, Türk Deprem Araştırma Dergisi 2019; 1(2): 134-147.

[12] SAP2000. Integrated finite element analysis and design of structures basic analysis reference manual, Computers and Structures 2012, California.

[13] Keskin E., Bozdoğan KB. 2007 ve 2018 deprem yönetmeliklerinin Kirklareli ili özelinde değerlendirilmesi, Kırklareli Üniversitesi Mühendislik ve Fen Bilimleri Dergisi 2018; 4(1): 74-90.

[14] Başaran V. Türkiye bina deprem yönetmeliğine (TBDY2019) göre Afyonkarahisar için deprem yüklerinin değerlendirilmesi, Afyon Kocatepe Üniversitesi Fen ve Mühendislik Bilimleri Dergisi 2018; 18(3): 1028-1035. 
[15] Hava Ş. Betonarme bir binanın eşdeğer deprem yükü yöntemi ile TDY 2007 ve TBDY 2018 yönetmeliklerine göre analizi, Yüksek Lisans Tezi, Konya Teknik Üniversitesi Lisansüstü Eğitim Enstitüsü, Konya, Türkiye, 2019. 